\title{
Maslinic acid potentiates the antitumor activities of gemcitabine in vitro and in vivo by inhibiting NF-kB-mediated survival signaling pathways in human gallbladder cancer cells
}

\author{
YONG YU $^{1 *}$, JINGHAN WANG ${ }^{1,2^{*}}$, NIANXIN XIA ${ }^{2 *}$, BIN LI $^{1}$ and XIAOQING JIANG ${ }^{1}$ \\ ${ }^{1}$ The First Department of Biliary Surgery, Eastern Hepatobiliary Surgical Hospital, The Second Military Medical University, \\ Shanghai 200438; ${ }^{2}$ Department of Hepatobiliary Surgery, Navy General Hospital of PLA, Beijing 100037, P.R. China
}

Received June 29, 2014; Accepted September 9, 2014

DOI: $10.3892 /$ or.2015.3755

\begin{abstract}
Gemcitabine (GEM) is one of the first-line drugs in the treatment of gallbladder cancer (GBC), although the therapeutic effect is not sustained due to resistance to the drug over time. Maslinic acid (MA) has been shown to inhibit transcription factor nuclear factor- $\mathrm{\kappa B}(\mathrm{NF}-\mathrm{\kappa B})$, resulting in the suppression of survival signaling. The authors of the present study investigated whether MA enhanced the antitumor activity of GEM in GBC. Anti-proliferative effects of MA, GEM and MA + GEM were assessed using the MTT assay. Apoptosis was assessed using Annexin V and by western blot analysis of various mediators of apoptosis. Xenograft tumors of EH-GB2 GBC cells were established in athymic nude mice and were monitored following treatment with MA, GEM and MA + GEM. Immunohistochemistry of the tumors was used to examine various survival proteins. MA inhibited the in vitro proliferation of various GBC cell lines and potentiated the apoptosis and cell invasion inhibition induced by GEM. Western blot analysis showed that the combination of MA and GEM inhibited constitutive NF- $\kappa \mathrm{B}$ activation and NF- $\kappa \mathrm{B}-$ regulated gene products, including cyclin D1, Bcl-2, Bax, MMP-2 and MMP-9, to a greater extent. In vivo, the group that was treated with MA + GEM showed significant reductions in tumor volume and a decreased expression of NF-kB-regulated gene products. In conclusion, the results suggest that MA potentiates the antitumor effects of GEM in human GBC cell lines by suppressing the activation of NF- $\mathrm{KB}$ and its dowstream gene products, which are involved in survival signaling.
\end{abstract}

Correspondence to: Dr Xiaoqing Jiang or Dr Bin Li, The First Department of Biliary Surgery, Eastern Hepatobiliary Surgical Hospital, The Second Military Medical University, 225 Changhai Road, Shanghai 200438, P.R. China

E-mail: jxq1225@sina.com

E-mail: libinjeff@126.com

*Contributed equally

Key words: gallbladder cancer, maslinic acid, gemcitabine, nuclear factor- $\kappa \mathrm{B}$, apoptosis

\section{Introduction}

Gallbladder cancer (GBC) is the most common cancer of the bile duct system and is the fifth most lethal cancer of the digestive system (1). The incidence of GBC in China, Thailand, Chile and Northern India is higher when compared with the United States and European countries (2). At present, radical surgical resection is the most effective treatment of GBC. However, for the majority of patients, surgery is not curative because of late detection and/or early, regional or distant metastasis. Additionally, few patients experience complete responses to chemotherapy, mainly due to chemoresistance. Thus, identifying novel approaches to enhance the antitumor effects of chemotherapeutic drugs and reduce chemoresistance are imperative.

Maslinic acid (MA), a pentacyclic triterpene acid, is widely present in dietary plants, especially in olive fruit skins and hawthorn berries (3). The compound has attracted much interest due to its proven pharmacological safety and its many biological activities, including anticancer such as anti-inflammation (2), anti-viral (4,5), anti-oxidation (6), anti-diabetogenic (7), anticolonic cancer $(8,9)$ and anti-astrocytoma (10) activities. MA has been shown to potentiate the anticancer activity of TNF- $\alpha$ in pancreatic cancer cells through the inhibition of nuclear factor- $\kappa \mathrm{B}(\mathrm{NF}-\kappa \mathrm{B})$ survival signaling pathways (11).

$\mathrm{NF}-\mathrm{\kappa B}$ is a transcriptional activator that has been extensively studied for its role in controlling the expression of genes involved in immune and inflammatory processes. The classical form of NF- $\kappa \mathrm{B}$ is a ubiquitous heterodimeric complex composed predominantly of IKK $\alpha / \beta$ and p65 subunits (12). In non-stimulated cells, NF- $\mathrm{KB}$ exists in an inactive form in the cytoplasm bound to an inhibitor, IкB $\alpha$. Aberrant or constitutive activation of NF- $\mathrm{kB}$ has been shown to stimulate cell growth and inhibit apoptosis in many human malignancies (13). The constitutive activation of NF- $\mathrm{kB}$ widely exists in many tumor types and may play a role in oncogenesis by stimulating cell growth, inhibiting apoptosis and promoting invasion $(14,15)$. Evidence suggests that NF- $\kappa \mathrm{B}$ may also be involved in tumor cell resistance to cancer chemotherapy and radiation (16). NF- $\mathrm{\kappa B}$ can be activated in response to treatment with anticancer drugs through a variety of mechanisms. For example, in HeLa cells, the topoisomerase I inhibitor SN38 
and the topoisomerase II inhibitor doxorubicin induce NF- $\mathrm{BB}$ nuclear translocation and activation of $\mathrm{NF}-\kappa \mathrm{B}$ target genes directly through mobilization and stimulation of the IKK complex, leading to increased cell survival (17). The activation of NF- $\kappa \mathrm{B}$ also leads to the transcription of genes that regulate cell growth, apoptosis, and invasion. Cyclin D1, Bcl-2, Bax, MMP-2 and MMP-9 are among the genes that are transcriptionally regulated by $\mathrm{NF}-\kappa \mathrm{B}(18)$.

Gemcitabine (GEM) is one of the few chemotherapeutic drugs used in the treatment of advanced and metastatic bile duct cancer and GBC $(19,20)$. However, GEM has been shown to induce chemoresistance in many types of cancer, including pancreatic (21), lung (22), ovarian (23), bladder (24) and biliary cancer (25).

It has been reported that MA significantly potentiates the antitumor activities of antitumor agents $(11,26)$. In this study, we investigated the effects of MA alone and in combination with GEM on human gallbladder carcinoma in vitro and in vivo, and its underlying mechanisms.

\section{Materials and methods}

Cell culture and reagents. GBC cell lines were reserved by the Eastern Hepatobiliary Surgery Institute. The gallbladder EH-GB1 (27), EH-GB2 (28), and GBC-SD human cancer cell lines were maintained in DMEM (Invitrogen, Carlsbad, CA, USA). The cells were regularly checked for mycoplasma by the PlasmoTest mycoplasma detection kit (InvivoGen, San Diego, CA, USA) and found to be negative. MA (>98\%) was purchased from Cayman (Ann Arbor, MI, USA) and was prepared as $20 \mathrm{mg} / \mathrm{ml}$ stock solutions in dimethyl sulfoxide (DMSO; Sigma Chemical, St. Louis, MO, USA) and stored at $-20^{\circ} \mathrm{C}$.

MTT and drug interaction analysis. For measurement of proliferation, the human GBC cell lines, EH-GB1, EH-GB2 and GBC-SD, were placed into 96-well plates at $1 \times 10^{4}$ cells/well. After $24 \mathrm{~h}$, the cells were treated with various concentrations of MA, GEM (Lilly, France) and MA + GEM. 3-(4,5-Dimethylthiazol-2-yl)-2,5-diphenyltetrazolium bromide (MTT) assays were performed to evaluate cell growth and viability. MTT solution was added to each well and incubated for $4 \mathrm{~h}$ at $37^{\circ} \mathrm{C}$. An extraction buffer (20\% SDS and $50 \%$ dimethylformamide) was added, and then cells were incubated overnight at $37^{\circ} \mathrm{C}$. The absorbance of the cell suspension was measured at $570 \mathrm{~nm}$ using a 96-well plate reader (Seeuco Electronics Technology Co., Ltd., China). Each experiment was repeated three times.

Drug interactions were quantified by median-dose effect analysis (29), and combination index values were derived using CompusSyn software (CompuSyn, Inc., Paramus, NJ, USA). CI values of $<1,=1$ and $>1$ indicated synergism, additivity, and antagonism, respectively, between the drugs.

Measurement of apoptosis. An Annexin V kit(BD Pharmingen, San Diego, CA, USA) was used to measure cell apoptosis. EH-GB1,EH-GB2 and GBC-SD cells were treated as described above. Annexin V and propidium iodide (PI) labeling followed, which was performed according to the manufacturer's instructions. The percentage of apoptosis in every group was analyzed by flow cytometry (Becton-Dickinson, Mountain View, CA, USA). Each experiment was repeated three times.

Migration assay. As previously described (11), EH-GB2 cells were allowed to grow until full confluence in 6-well plates. Monolayer GBC cells were wounded by scratching with a $1 \mathrm{ml}$ pipette tip. DMSO solution, MA, GEM, and MA + GEM were added respectively to plates at indicated concentrations. Images were captured using a Olympus digital camera after $10 \mathrm{~h}$ of incubation at $37^{\circ} \mathrm{C}$ and $5 \% \mathrm{CO}_{2}$. The migrated cells were quantified by manual counting, and percentage inhibition was expressed using untreated wells at $100 \%$.

Invasion assay. To test the effect of MA on cell invasion activity, we performed Transwell invasion assays as previously described (30). Briefly, starved cells (1x10 $/$ well) were seeded in the top chambers of the Transwell with an $8-\mu \mathrm{m}$ pore polycarbonate filter insert coated with $0.1 \%$ gelatin (both from Corning, New York, NY, USA). The bottom chambers were filled with DMEM with 10\% FBS supplemented with or without $0.1 \mathrm{nM}$ GEM. The top and bottom chamber contained the same concentration of MA. EH-GB2 cells were allowed to migrate for $12 \mathrm{~h}$. The cells were scraped on the top surface of the membrane and stained. The cells on the bottom side of the membranes (migrated cells) were counted using an Olympus inverted microscope.

Western blot analysis. Western blot analysis was performed to determine the effect of MA and GEM on NF- $\kappa B$ nuclear translocation and various $\mathrm{NF}-\kappa \mathrm{B}$-regulated genes. Cell lysates (40 $\mu \mathrm{g}$ ) were resolved by SDS-PAGE. After electrophoresis, the proteins were electro-transferred to nitrocellulose membranes (Bio-Rad Laboratories, Hercules, CA, USA), blotted with the relevant antibody, and detected by an enhanced chemiluminescence reagent (Amersham, Piscataway, NJ, USA). Antibodies to phosho-I $\mathrm{B} \alpha, \mathrm{I} \kappa \mathrm{B} \alpha$ and p65 (1:1,000 dilutions) were purchased from Thermo Scientific (Rockford, IL, USA). Antibodies for $\beta$-actin, cyclin D1, Bcl-2, Bax, MMP-9 and MMP-2 (1:1,000 dilutions) were purchased from Santa Cruz Biotechnology, Inc. (Santa Cruz, CA, USA).

Mouse xenograft model and tumor treatment. Xenograft mouse models were performed as previously described (31). Six-week-old athymic nu/nu male mice were purchased from SIBS (Shanghai, China). The experiments performed on the animals were approved by the Animal Ethics Committee of the Second Military Medical University prior to the study. EH-GB2 tumor cells were subcutaneously injected into the mice $\left(2 \times 10^{6}\right.$ cells/mouse).

After the tumors were established $\left(\sim 100 \mathrm{~mm}^{3}\right)$, the mice were randomized into the following treatment groups $(n=5)$ : i) untreated control; ii) subcutaneously injected with $30 \mathrm{mg} / \mathrm{kg}$ bodyweight of MA every 2 days for 30 days; iii) GC $50 \mathrm{mg} / \mathrm{kg}$ of bodyweight intraperitoneal every 2 for 30 days; and iv) MA and GEM following the schedule for the individual treatments. The control mice were injected with DMSO. The mice body weight and tumor sizes were recorded every other day, and the tumor size was determined by vernier caliper measurements and calculated as maximal diameter $\mathrm{x}$ minimal diameter $^{2} \mathrm{x} 0.5$ (32). After 36 days, mice with tumors were 
A
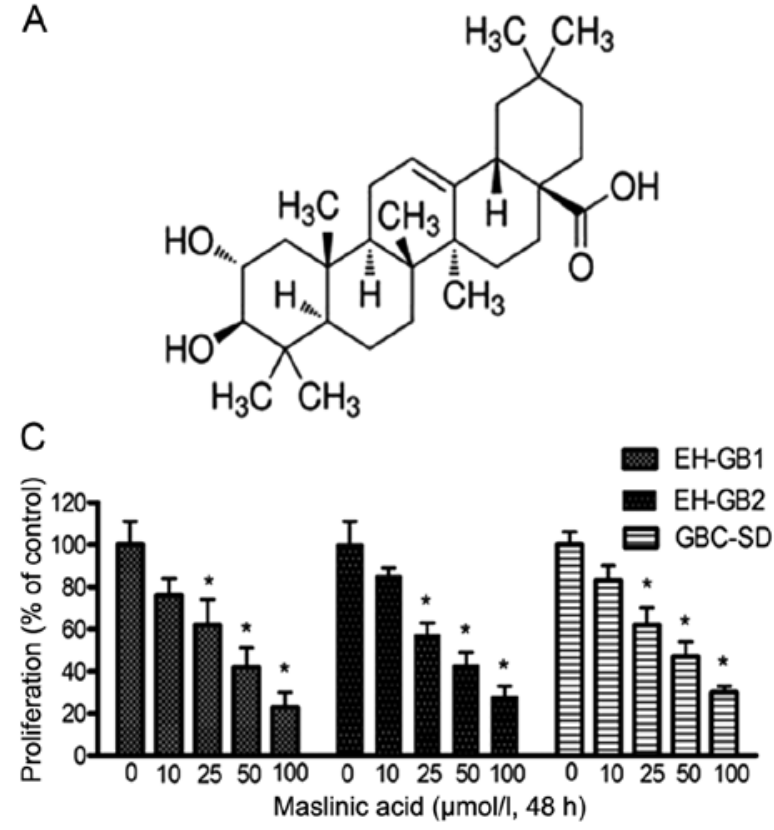
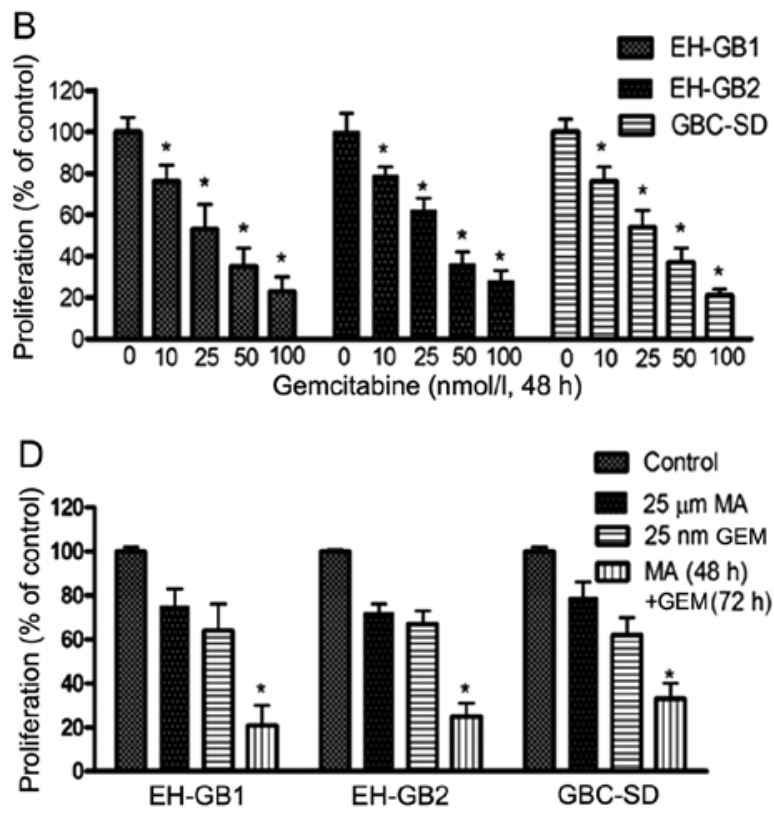

Figure 1. Maslinic acid (MA) increases gemcitabine (GEM) anti-proliferative activity in gallbladder cancer (GBC) cells. (A) Structure of MA [(2 $\alpha, 3 \beta)-2,3-$ dihydroxyolean-12-en-28-oic acid]. (B) MA inhibited GBC cell line proliferation in a dose-dependent manner and this inhibitory effect was significantly increased at $25 \mu \mathrm{mol} / 1$. (C) GEM inhibited cell proliferation in a dose-dependent manner. (D) The inhibition of cell proliferation by GEM (25 nmol/1) and MA $(25 \mu \mathrm{mol} / \mathrm{l})$ in combination. Cell growth was evaluated by the MTT method. Bars, mean $\pm \mathrm{SD}$. * $\mathrm{P}<0.05$ vs. non-treated group.

sacrificed. One section of the tissue was fixed in formalin and another section was frozen in liquid nitrogen.

Histology and immunohistochemistry (IHC). After the tumors were removed, they were weighed, fixed with $10 \%$ formalin, and embedded with paraffin. H\&E and IHC for Bcl-2 and Bax were performed on paraffin-embedded tissue sections. The rabbit antibodies against Bcl-2 and Bax were purchased from Santa Cruz Biotechnology, Inc. and applied for IHC staining (1:1,000 dilution). PBS was used as a negative control. After IHC was performed, images from each group were captured using an Olympus BX60 upright microscope (Olympus, Tokyo, Japan).

Terminal deoxynucleotidyltransferase-mediated dUTP nick end-labelling (TUNEL) staining. Apoptotic cells in EH-GB2 tumor xenograft tissue sections were detected by TUNEL using a commercially available kit (EMD Millipore Corporation, Billerica, MA, USA). The tissue sections were processed according to the manufacturer's instructions.

Statistical analysis. Data are presented as mean \pm SD as indicated in the vertical axis of figures. The statistical significance of differential findings between experiments and controls was determined by using the Student's t-test or analysis of variance (ANOVA). Statistical analyses were computed with SPSS 13.0 (SPSS Inc., Chicago, IL, USA). Statistical significance was $\mathrm{P}<0.05$ unless otherwise stated.

\section{Results}

MA inhibits proliferation, and potentiates the apoptosis induced by GEM. We first examined the effects of MA (Fig. 1A), GEM and MA + GEM on the proliferation of human
GBC cells (EH-GB1, EH-GB2 and GBC-SD) using the MTT assay. The results showed that MA and GEM as single agents both inhibited the proliferation of the GBC cell lines in a dosedependent manner (Fig. 1B and C). MA and GEM combined significantly inhibited cell proliferation of all three GBC cell lines (Fig. 1D). A combination index (23) was calculated for all combinations of GEM and MA examined in the three cell lines, indicating that the interaction between the two drugs was synergistic (Fig. 2).

Subsequently, we examined whether the inhibition of cell proliferation was due to enhanced apoptosis with the combination of MA and GEM compared to single agents. Accordingly, relative to the single agents, MA treatment $(25 \mu \mathrm{mol} / \mathrm{l})$ followed by GEM treatment elicited significantly $(\mathrm{P}<0.05)$ higher apoptosis in the investigated cancer cell lines, suggesting that the loss of viable cells by MA + GEM was due to the induction of cell death pathways (Fig. 3A).

MA enhances the inhibition of GEM in cancer cell migration and invasion. Migration assays were performed to determine the effects of MA on EH-GB2 migration. We found that the combination of MA and GEM strongly inhibited the migration of EH-GB2 cells (Fig. 3B). We performed Transwell assays to evaluate the ability of EH-GB2 to filter through the membrane barrier after treatment with MA, GEM and MA + GEM. MA, at low concentrations of $10 \mu \mathrm{mol} / 1$, significantly potentiated the properties of GEM, inhibiting cancer cell invasion (Fig. 3C).

$N F-\kappa B$ activation is inhibited by the combination of MA and GEM. We examined whether the combination of MA and GEM was able to inhibit NF- $\mathrm{B}$ activation. EH-GB1 and EH-GB2 cells were incubated with suboptimal concentrations of MA and GEM alone and in combination. IKK $\alpha / \beta$ and p65 activation were determined by western blot analysis. MA potentiated 

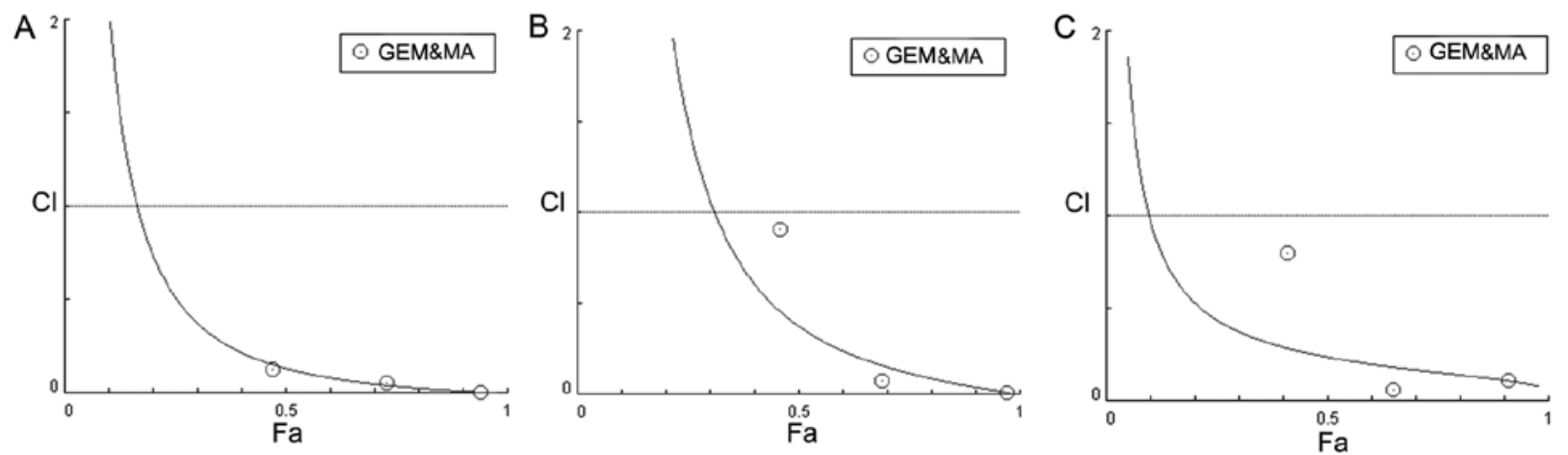

Figure 2. Combination index plots of maslinic acid (MA) + gemcitabine (GEM) of (A) EH-GB1, (B) EH-GB2 and (C) gallbladder cancer (GBC)-SD.
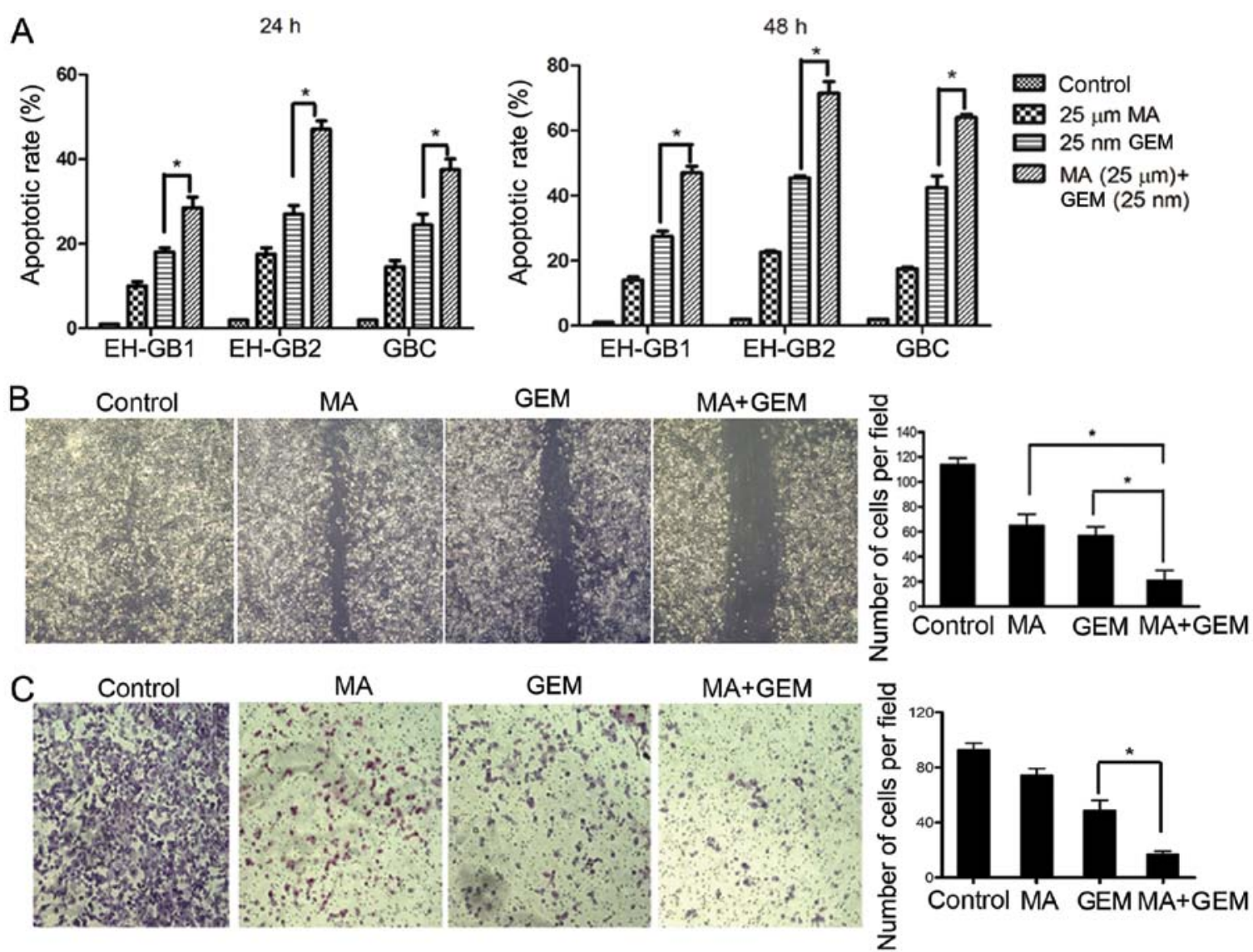

Figure 3. Maslinic acid (MA) enhances the inhibition of gemcitabine (GEM) in cancer cell apoptosis and invasion. (A) Effects of MA on the apoptosis of EH-GB1, EH-GB2 and gallbladder cancer (GBC) cell lines at 24 and $48 \mathrm{~h}$. (B) The Transwell invasion assay showed that GEM combined with MA significantly inhibited the migration of the EH-GB2 cell line. (C) Effects of MA on the invasion of EH-GB2 using the Transwell assay. Bars, mean \pm SD. "P<0.05 vs. non-treated group.

the inhibitory effect of GEM on p65 nuclear translocation and phosphorylation in GBC cells (Fig. 4).

MA potentiates the effect of GEM in downregulating the expression of $N F-\kappa B$-regulated gene products in vitro. We examined the effect of MA on the expression of NF- $\mathrm{kB}$-regulated gene products involved in cell proliferation (cyclin D1), apoptosis (Bax and Bcl-2), and metastasis (MMP-2 and MMP-9) (Fig. 5). The cells were exposed to MA ( $25 \mu \mathrm{mol} / \mathrm{l})$ for $48 \mathrm{~h}$ prior to the addition of GEM for $24 \mathrm{~h}$. The results showed that the expression of cyclin D1 and Bcl-2 were significantly downregulated in the combination group compared with the individual treatment groups. By contrast, Bax expression was substantially increased after the combinatorial treatment when compared to single agents. Furthermore, the activities of MMP-2 and MMP-9 were significantly reduced by the treatment with MA + GEM.

MA potentiates the antitumor effects of GEM in vivo. To determine whether MA enhances the antitumor effects of GEM in GBC, we established a human GBC xenograft in nude mice using EH-GB2 cells. Treatment was initiated 
A

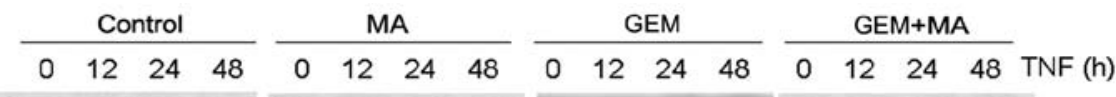

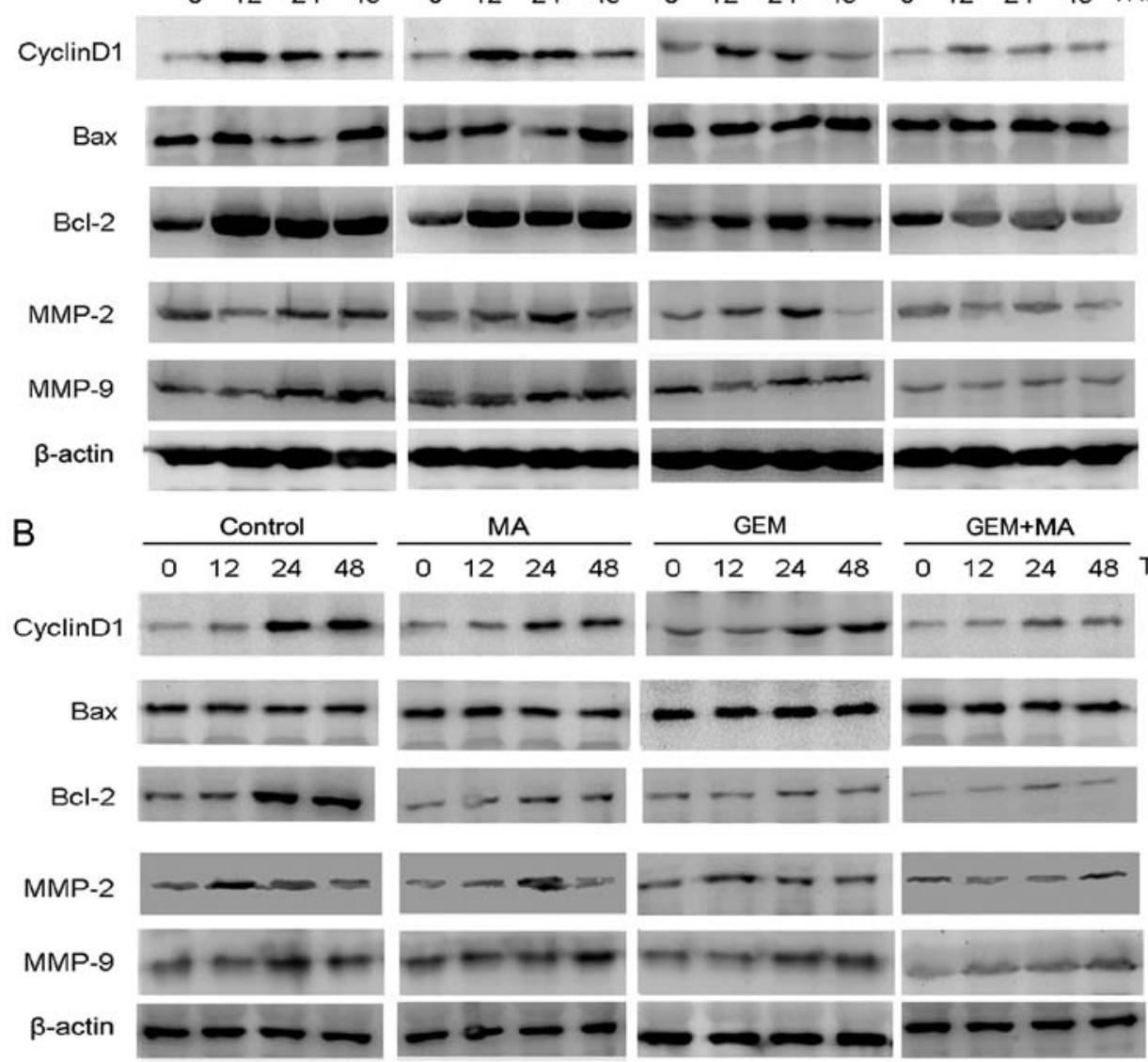

Figure 4. The treatment of maslinic acid (MA) + gemcitabine (GEM) alters the expression of cyclin D1, Bax, Bcl-2, MMP-2 and MMP-9. Various mediators of survival signaling and apoptosis were assessed by western blot analysis. (A) EH-GB1 and (B) EH-GB2 were treated with cell medium containing $25 \mathrm{nmol} / 1$ GEM alone or combined with $25 \mu \mathrm{mol} / 1 \mathrm{MA}$ for $0,12,24$ and $48 \mathrm{~h}$. $\beta$-actin protein was used as the internal control.

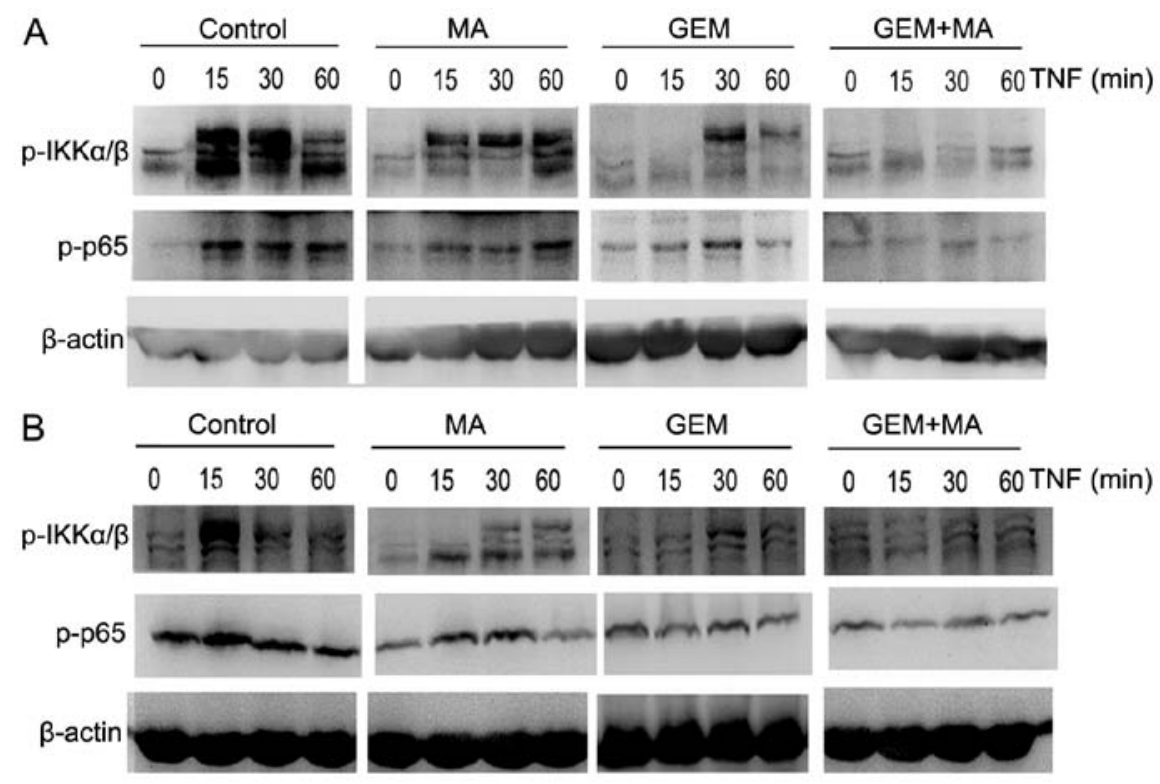

Figure 5. NF-кB activities can be inhibited by combined treatment with gemcitabine (GEM) and maslinic acid (MA) western blot analysis for IKK $\alpha / \beta$ and p65 subunit of (A) EG-GB1 and (B) EH-GB2 cells treated with cell medium, GEM, MA or MA + GEM. TNF- $\alpha$ was used as the irritant, and $\beta$-actin protein was used as the internal control.

1 week after tumor cell implantation and was continued up to 28 days (Fig. 6A). The tumor diameters were measured at 1-week intervals. Animals were sacrificed 35 days after tumor cell injection and 28 days after the treatment initiation date. 


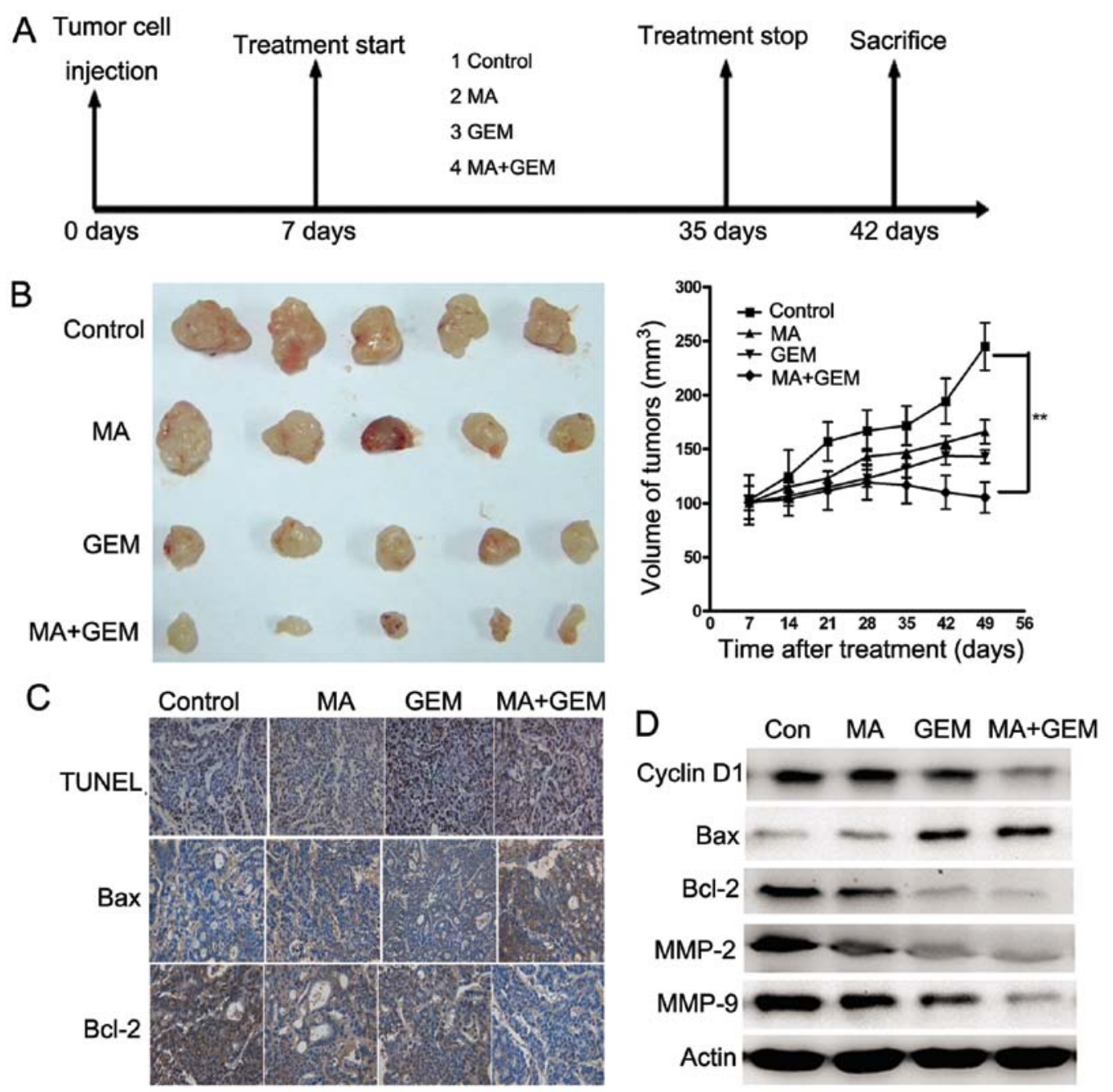

Figure 6. The treatment of gemcitabine (GEM) combined with maslinic acid (MA) leads to potent growth inhibition, apoptosis and invasion of EH-GB2 cells in vivo. (A) Protocol of animal treatment. (B) Changes in the isolated tumor volume and weight showing efficacy of GEM and MA combinatorial therapy. (C) Terminal deoxynucleotidyltransferase-mediated dUTP nick end-labelling (TUNEL) assay and immunohistochemical analysis (Bax and Bcl-2) for evaluation and quantification of apoptosis in EH-GB2 tumor sections. (D) Western blot assay for relative protein of cyclin D1, Bax, Bcl-2, MMP-2 and MMP-9 obtained from the isolated tumor tissue. They were quantified by measuring the band intensities of the three separate experiments. Bars, mean $\pm \mathrm{SD}$. ${ }^{*} \mathrm{P}<0.05$ vs. non-treated group.

At this time the tumors were excised and the tumor diameters were measured. We found that the tumor volume increased rapidly in the control group compared with the other treatment groups (Fig. 6B). MA alone and GEM alone moderately decreased the tumor volume. However, the tumor volume in the combination group was significantly lower than that in the GEM and MA alone groups at day 28 after treatment $(\mathrm{P}<0.05)$.

TUNEL staining of xenograft sections. To investigate whether MA potentiated GEM-induced apoptosis in vivo, we stained the solid tumor sections with an apoptosis staining kit. Significant differences in the percentage of TUNEL-positive cells were noted in tumors derived from the combination group relative to the single treatment groups $(\mathrm{P}<0.05)$.

Immunohistochemical and western blot analyses. Various mediators of apoptosis and survival signaling were also examined in tumors collected from the xenograft study. The expression level of $\mathrm{Bcl}-2$ was significantly decreased, while Bax was increased by IHC staining (Fig. 6C). The same trend of Bcl-2 and Bax was identified in western blot assay (Fig. 6D). The expression of cyclin D1, MMP-2 and MMP-9, which were involved in tumor progression, was inhibited significantly by combining MA and GEM (Fig. 6D).

\section{Discussion}

MA, a natural triterpenoid that can be extracted from olive skin, has been assessed for its antitumoral property in colonic cancer (10), melanoma $(33,34)$, and astrocytoma (35) cells. GEM, which is a nucleoside analog of deoxycytidine that inhibits DNA synthesis (36), has been increasingly prescribed for GBC. Findings of recent studies have focused on improving the drug efficacy by combining GEM with other agents $(37,38)$. We designed this study to determine whether MA can sensitize GBC to GEM.

The constitutive activation of NF- $\mathrm{KB}$ is associated with the growth and survival of cancer cells (39). In addition, studies have shown that MA suppressed NF-kB activation (40). In the present study, we investigated the mechanism of how 
MA enhanced the apoptotic effects of GEM in cultured GBC cells. In vitro, we have demonstrated that MA enhanced GEM-induced apoptosis and suppressed NF- $\mathrm{KB}$ activity. A recent review by Nakanishi and Toi (41) details the activation of NF- $\kappa \mathrm{B}$ by chemotherapeutic agents as the major factor contributing to chemoresistance. MA can inhibit IKK $\alpha / \beta$ degradation, block p65 nuclear translocation and phosphorylation, and downregulate the expression levels of $\mathrm{NF}-\mathrm{\kappa B}-$ mediated genes/proteins involved in proliferation, apoptosis and invasion (42). As previously reported, proteins including cyclin D1, Bax, Bcl-2, MMP-2 and MMP-9, have been associated with tumor growth, apoptosis, invasion, and metastasis. In previous studies, it was shown that combining a NF- $\mathrm{kB}$ inhibitor with a front-line anticancer drug enhances the overall antitumor response $(43,44)$. In this study, we have concluded that the downregulation of NF- $\mathrm{KB}$ by MA can enhance the sensitivity of GBC cells to GEM.

Our in vitro results were recapitulated in vivo in a subcutaneous xenograft GBC model, wherein MA significantly enhanced the antitumor efficacy of chemotherapeutics. Although none of the mice from the combinatorial treatment group were tumor-free, the therapeutic effect was significant compared with single-drug treatment. These findings are concomitant with increased TUNEL staining and reduced MA and GEM immunoreactivity indicative of apoptosis and reduced cell proliferation within tumors. These features are of significant value in predicting improved therapeutic outcomes and require further investigation.

Given the pharmacologic safety of MA (45), our studies suggest that this compound has great potential as a chemopreventive and a chemotherapeutic agent, especially when used in combination with existing agents. Whether the concentrations of MA used in our studies are achievable in the clinic remains to be determined. MA metabolism in the cells is also unclear at present. Our results also show that patient-derived

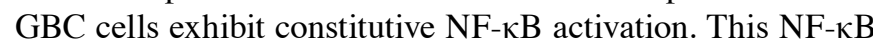
activation was suppressed significantly by GEM in combination with MA, thus leading to the inhibition of proliferation, apoptosis and invasion of the cells.

In this study, MA decreased the protein expression of cyclin D1, which is a cell cycle-positive regulator, indicating a role for MA in GBC proliferation (46). Cyclin D1 adversely affects clinical outcomes and serves as an independent marker in predicting decreased survival for patients with $\operatorname{GBC}(47,48)$.

In the present study, the cells treated with GEM and MA had a downregulated anti-apoptotic Bcl-2, but an increased expression of pro-apoptotic Bax. The Bcl-2 family is important in the regulation of apoptosis and comprises pro-apoptotic and anti-apoptotic members (49). In EH-GB1 and EH-GB2 cell lines, Bcl-2 was significantly downregulated and Bax was upregulated in the combination group when compared with the GEM treatment group and the non-treated control group.

MMPs are central mediators of tumor metastasis due to their ability to degrade basement membrane and extracellular matrix components (50). MMP-2 and MMP-9 expression is positively associated with Nevin stage, distant metastasis, and the degree of histological differentiation in GBC (51). The results showed that MA inhibited the invasion of GBC by reducing MMP-2 and MMP-9 activation through the suppression of NF- $\mathrm{kB} / \mathrm{p} 65$ activation.
In conclusion, to the best of our knowledge, this is the first study to demonstrate that MA can potentiate GEM activity in vitro and in vivo in GBC models. The results suggest that MA is a potentially valuable agent in the development of a new class of drugs to assist in potentiating the anticancer effects of conventional chemotherapeutics targeting specific pathways for the treatment of human GBC. Future studies should be conducted in the clinical setting to validate the biological relevance of these results.

\section{Acknowledgements}

This study was supported by the General Program (81172019) from the National Science Foundation of China.

\section{References}

1. Matsuba T, Qiu D, Kurosawa M, et al; JACC Study Group: Overview of epidemiology of bile duct and gallbladder cancer focusing on the JACC Study. J Epidemiol 15 (Suppl 2): S150-S156, 2005.

2. Randi G, Malvezzi M, Levi F, et al: Epidemiology of biliary tract cancers: an update. Ann Oncol 20: 146-159, 2009.

3. Tchivounda HP, Koudogbo B, Besace Y and Casadevall E: Triterpene saponins from Cylicodiscus gabunensis. Phytochemistry 30: 2711-2716, 1991.

4. Xu HX, Zeng FQ, Wan M and Sim KY: Anti-HIV triterpene acids from Geum japonicum. J Nat Prod 59: 643-645, 1996.

5. Serra C, Lampis G, Pompei R and Pinza M: Antiviral activity of new triterpenic derivatives. Pharmacol Res 29: 359-366, 1994.

6. Montilla MP, Agil A, Navarro MC, et al: Antioxidant activity of maslinic acid, a triterpene derivative obtained from Olea europaea. Planta Med 69: 472-474, 2003.

7. Liu J, Sun H, Duan W, Mu D and Zhang L: Maslinic acid reduces blood glucose in KK-Ay mice. Biol Pharm Bull 30: 2075-2078, 2007.

8. Reyes-Zurita FJ, Rufino-Palomares EE, Lupianez JA and Cascante M: Maslinic acid, a natural triterpene from Olea europaea L., induces apoptosis in HT29 human colon-cancer cells via the mitochondrial apoptotic pathway. Cancer Lett 273: 44-54, 2009.

9. Juan ME, Planas JM, Ruiz-Gutierrez V, Daniel H and Wenzel U: Antiproliferative and apoptosis-inducing effects of maslinic and oleanolic acids, two pentacyclic triterpenes from olives, on HT-29 colon cancer cells. Br J Nutr 100: 36-43, 2008.

10. Martin R, Carvalho-Tavares J, Ibeas E, Hernandez M, Ruiz-Gutierrez V and Nieto ML: Acidic triterpenes compromise growth and survival of astrocytoma cell lines by regulating reactive oxygen species accumulation. Cancer Res 67: 3741-3751, 2007.

11. Li C, Yang Z, Zhai C, et al: Maslinic acid potentiates the antitumor activity of tumor necrosis factor alpha by inhibiting NF-kappaB signaling pathway. Mol Cancer 9: 73, 2010.

12. Lafarge S, Hamzeh-Cognasse H, Richard Y, et al: Complexes between nuclear factor- $\kappa \mathrm{B}$ p 65 and signal transducer and activator of transcription 3 are key actors in inducing activationinduced cytidine deaminase expression and immunoglobulin $\mathrm{A}$ production in CD40L plus interleukin-10-treated human blood B cells. Clin Exp Immunol 166: 171-183, 2011.

13. Ozes ON, Mayo LD, Gustin JA, Pfeffer SR, Pfeffer LM and Donner DB: NF-kappaB activation by tumour necrosis factor requires the Akt serine-threonine kinase. Nature 401: 82-85, 1999.

14. Mori N, Fujii M, Ikeda S, et al: Constitutive activation of NF-kappaB in primary adult T-cell leukemia cells. Blood 93: 2360-2368, 1999.

15. Ma G, Tabanca N, Husnu Can Baser K, et al: Inhibition of NF-kappaB-mediated transcription and induction of apoptosis in human breast cancer cells by epoxypseudoisoeugenol-2-methyl butyrate. Cancer Chemother Pharmacol 63: 673-680, 2009.

16. Camp ER, Li J, Minnich DJ, et al: Inducible nuclear factor-kappaB activation contributes to chemotherapy resistance in gastric cancer. J Am Coll Surg 199: 249-258, 2004.

17. Bottero V, Busuttil V, Loubat A, et al: Activation of nuclear factor kappaB through the IKK complex by the topoisomerase poisons SN38 and doxorubicin: a brake to apoptosis in HeLa human carcinoma cells. Cancer Res 61: 7785-7791, 2001. 
18. Arlt A, Vorndamm J, Breitenbroich M, et al: Inhibition of NF-kappaB sensitizes human pancreatic carcinoma cells to apoptosis induced by etoposide (VP16) or doxorubicin. Oncogene 20: 859-868, 2001

19. Doval DC, Sekhon JS, Gupta SK, et al: A phase II study of gemcitabine and cisplatin in chemotherapy-naive, unresectable gall bladder cancer. Br J Cancer 90: 1516-1520, 2004.

20. Penz M, Kornek GV, Raderer M, et al: Phase II trial of twoweekly gemcitabine in patients with advanced biliary tract cancer. Ann Oncol 12: 183-186, 2001.

21. Desai S, Ben-Josef E, Griffith KA, et al: Gemcitabine-based combination chemotherapy followed by radiation with capecitabine as adjuvant therapy for resected pancreas cancer. Int J Radiat Oncol Biol Phys 75: 1450-1455, 2009.

22. Scagliotti GV, Parikh P, von Pawel J, et al: Phase III study comparing cisplatin plus gemcitabine with cisplatin plus pemetrexed in chemotherapy-naive patients with advanced-stage non-small-cell lung cancer. J Clin Oncol 26: 3543-3551, 2008.

23. Ferrandina G, Ludovisi M, Lorusso D, et al: Phase III trial of gemcitabine compared with pegylated liposomal doxorubicin in progressive or recurrent ovarian cancer. J Clin Oncol 26: 890-896, 2008

24. Shelley M, Cleves A, Wilt TJ and Mason M: Gemcitabine for unresectable, locally advanced or metastatic bladder cancer Cochrane Database Syst Rev: April 13, 2011 (Epub ahead of print) doi: 10.1002/14651858.CD008976.pub2 .

25. Knox JJ, Hedley D, Oza A, et al: Combining gemcitabine and capecitabine in patients with advanced biliary cancer: a phase II trial. J Clin Oncol 23: 2332-2338, 2005.

26. Mooi LY, Wahab NA, Lajis NH and Ali AM: Chemopreventive properties of phytosterols and maslinic acid extracted from Coleus tuberosus in inhibiting the expression of EBV earlyantigen in Raji cells. Chem Biodivers 7: 1267-1275, 2010.

27. Li LF, Hu HZ, Liu C, et al: Establishment and characterization of a human gallbladder carcinoma cell line EH-GB1 originated from a metastatic tumor. Zhonghua Zhong Liu Za Zhi 32: 84-87, 2010 (In Chinese)

28. Wang JH, Li LF, Yu Y, et al: Establishment and characterization of a cell line, EH-GB2, derived from hepatic metastasis of gallbladder cancer. Oncol Rep 27: 775-782, 2012

29. Chou TC: Drug combination studies and their synergy quantification using the Chou-Talalay method. Cancer Res 70: 440-446, 2010.

30. Klein CA: Cancer. The metastasis cascade. Science 321: 1785-1787, 2008.

31. Karin M: Nuclear factor-kappaB in cancer development and progression. Nature 441: 431-436, 2006.

32. Carlsson G, Gullberg B and Hafström L: Estimation of liver tumor volume using different formulas - an experimental study in rats. J Cancer Res Clin Oncol 105: 20-23, 1983.

33. Lee $\mathrm{CH}$, Jeon YT, Kim SH and Song YS: NF-kappaB as a potential molecular target for cancer therapy. Biofactors 29: 19-35, 2007.

34. Li F and Sethi G: Targeting transcription factor NF-kappaB to overcome chemoresistance and radioresistance in cancer therapy. Biochim Biophys Acta 1805: 167-180, 2010.

35. Ueno H, Kiyosawa K and Kaniwa N: Pharmacogenomics of gemcitabine: can genetic studies lead to tailor-made therapy? $\mathrm{Br}$ J Cancer 97: 145-151, 2007.
36. Knudsen KE, Diehl JA, Haiman CA and Knudsen ES: Cyclin D1: polymorphism, aberrant splicing and cancer risk. Oncogene 25 : $1620-1628,2006$

37. Fan YZ, Fu JY, Zhao ZM and Chen CQ: Inhibitory effect of norcantharidin on the growth of human gallbladder carcinoma GBC-SD cells in vitro. Hepatobiliary Pancreat Dis Int 6: 72-80, 2007.

38. Ma HB, Hu HT, Di ZL, et al: Association of cyclin D1, p16 and retinoblastoma protein expressions with prognosis and metastasis of gallbladder carcinoma. World J Gastroenterol 11: 744-747, 2005.

39. Reyes-Zurita FJ, Pachón-Peña G, Lizárraga D, RufinoPalomares EE, Cascante M and Lupianez JA: The natural triterpene maslinic acid induces apoptosis in HT29 colon cancer cells by a JNK-p53-dependent mechanism. BMC Cancer 11: 154, 2011.

40. Parra A, Rivas F, Martin-Fonseca S, Garcia-Granados A and Martinez A: Maslinic acid derivatives induce significant apoptosis in b16f 10 murine melanoma cells. Eur J Med Chem 46: 5991-6001, 2011

41. Nakanishi $\mathrm{C}$ and Toi M: Nuclear factor-kappaB inhibitors as sensitizers to anticancer drugs. Nat Rev Cancer 5: 297-309, 2005.

42. Zhu AX, Hong TS, Hezel AF and Kooby DA: Current management of gallbladder carcinoma. Oncologist 15: 168-181, 2010.

43. Bauer JA, Lupica JA, Schmidt H, et al: Nitrosylcobalamin potentiates the anti-neoplastic effects of chemotherapeutic agents via suppression of survival signaling. PLoS One 2: e1313, 2007.

44. Chawla-Sarkar M, Bauer JA, Lupica JA, et al: Suppression of NF-kappa B survival signaling by nitrosylcobalamin sensitizes neoplasms to the anti-tumor effects of Apo2L/TRAIL. J Biol Chem 278: 39461-39469, 2003.

45. Guan T, Qian Y, Tang X, et al: Maslinic acid, a natural inhibitor of glycogen phosphorylase, reduces cerebral ischemic injury in hyperglycemic rats by GLT-1 up-regulation. J Neurosci Res 89: 1829-1839, 2011.

46. Chao DT and Korsmeyer SJ: BCL-2 family: regulators of cell death. Annu Rev Immunol 16: 395-419, 1998.

47. Boise LH, Gottschalk AR, Quintans J and Thompson CB: Bcl-2 and Bcl-2-related proteins in apoptosis regulation. Curr Top Microbiol Immunol 200: 107-121, 1995.

48. Fahy BN, Schlieman MG, Mortenson MM, Virudachalam S and Bold RJ: Targeting BCL-2 overexpression in various human malignancies through NF-kappaB inhibition by the proteasome inhibitor bortezomib. Cancer Chemother Pharmacol 56: 46-54, 2005.

49. Pulukuri SM and Rao JS: Matrix metalloproteinase-1 promotes prostate tumor growth and metastasis. Int J Oncol 32: 757-765, 2008.

50. Wu W, Wang R, Liu H, et al: Prediction of prognosis in gallbladder carcinoma by CD147 and MMP-2 immunohistochemistry. Med Oncol 26: 117-123, 2009.

51. Park SY, Nho CW, Kwon DY, Kang YH, Lee KW and Park JH: Maslinic acid inhibits the metastatic capacity of DU145 human prostate cancer cells: possible mediation via hypoxia-inducible factor-1 $\alpha$ signalling. Br J Nutr 109: 210-222, 2013. 